\title{
Demographic profile of autopsy in Indore region - One year prospective study
}

\author{
Rahul Agrawal ${ }^{1}$, P. S. Thakur ${ }^{2}$, Mohit Shrivastava, ${ }^{3, *}$ B.K. Singh ${ }^{4}$, T. S. Pendro ${ }^{5}$ \\ ${ }^{1,3}$ PG Resident, ${ }^{2}$ Professor and HOD, ${ }^{4}$ Associate Professor, ${ }^{5}$ Assistant Professor, Dept. of Forensic Medicine \& Toxicology, M.G.M. \\ Medical College \& M.Y. Hospital, Indore, Madhya Pradesh, India \\ *Corresponding Author: Mohit Shrivastava \\ Email: dr.mohit11@yahoo.com
}

\begin{abstract}
The term 'Autopsy' originates from ancient 'Autopsia' which is derived from 'Autos' i.e. 'Oneself' and 'Opsis' i.e. 'to see for oneself'. Medico-legal postmortem examinations are performed as mandatory legal procedures for establishing the cause of death for people dying in circumstances where multiple causes of death could be ascribed. The present prospective study was carried out in the Department of Forensic Medicine \& Toxicology, M.G.M. Medical College \& M.Y. Hospital, Indore during the period from 1st August 2017 to 31 st July 2018 which includes a total 2197 cases of death, brought to the mortuary of the hospital for medico-legal postmortem examination. The main objectives of the study were: to ascertain the various aspects of unnatural deaths, to analyze the probable reasons for the same \& to find remedial measures to bring down the incidence. During the study period 2197 cases were analyzed in which $609(27.8 \%)$ were females and $1588(72.2 \%)$ were males. Major causes of death comprises trauma 818 (37.2\%) burn $277(12.6 \%)$ poisoning $238(10.8 \%)$ asphyxia $237(10.7 \%)$ and multiple pathology $146(6.6 \%)$. Opinion about the cause of death was reserved in 310 (14.1\%). This study was conducted to determine and evaluate the socio-demographic profile of different types of cases and to assess the nature and cause of their death.
\end{abstract}

Keywords: Autopsy, Demography, Alleged manner of death.

\section{Introduction}

Medicolegal postmortem examinations are performed under the Section 174 of the Criminal Procedure Code, $1973^{1}$ for establishing the cause of death in cases where persons die in possible unnatural circumstances. Autopsy (also known as postmortem examination or necropsy) is performed to determine the identity of the deceased, when not known; ascertain the time since death and the cause of death; and find out whether the cause of death was natural or unnatural and if unnatural, whether it was homicidal, suicidal, or accidental. ${ }^{2}$

The term "postmortem examination" is often used as a simile for "autopsy." Basically, it is not. ${ }^{3}$ A postmortem examination means only what it says that the body was examined after death. It can mean and often does mean that the physician merely looked at the body, fully clothed, or that he "viewed" the body at a funeral home or in a morgue. A complete autopsy involves opening all body cavities and all organs of the trunk, chest, and head. ${ }^{4}$

The term 'ACCIDENT' has been defined as an occurrence in the sequence of events which usually produces unintended injury, death or property damage. ${ }^{5}$ It is also defined as "an unexpected, unplanned occurrence which may involve injury". ${ }^{6}$

Burn may be defined as the traumatic effects of application of physical heat in any form to the body. Fire deaths are some of the most challenging fatalities, both from the investigative and the autopsy aspect. ${ }^{7}$

Poison is a substance which has deleterious effect on living organisms produces ill health or death by direct contact or by absorption in the body. With advancement in science and technology large number of harmful chemicals especially insecticides and pesticides are invented to protect farming. But now they become a serious threat to human lives. $^{8}$
In India, hanging is second common method of committing suicide after poisoning. Over the past 30 years the incidence of suicide by hanging is on increase, especially among young adults. ${ }^{9}$

This study aims to describe the demographic profile and analyzes the causes of deaths certified after postmortem examinations, in order to facilitate improved and more reliable certification of the cause of death.

\section{Materials and Methods}

The present prospective study was carried out in the Department of Forensic Medicine \& Toxicology, M.G.M. Medical College \& M.Y. Hospital, Indore (M.P.) during the period from 1st August 2017 to 31st July 2018 and analysis a total of 2197 cases, brought to the mortuary of the hospital for medico-legal postmortem examination.

Details of the cases were collected like age, sex, major cause of death, month wise distribution of the cases, alleged manner of death etc. from the police papers, the inquest reports and hospital records. The information was compiled, tabulated and analyzed.

\section{Observations and Results}

The total number of postmortem examinations conducted during the study period was 2197 out of which $609(27.8 \%)$ were females and $1588(72.2 \%)$ were males. [Fig. 1] $1665(75.8 \%)$ cases were from the working-age population (21-60 years of age). 35 (1.5\%) cases were non viable fetus, $70(3.1 \%)$ cases were in age group between 0 10 years and $154(7.0 \%)$ cases were above 61 years of age. [Table 1] Age, religion, and place of residence could not be determined in $152(6.9 \%)$ cases.

Major causes of death comprises trauma 818 (37.2\%) burn $277(12.6 \%)$ poisoning $238(10.8 \%)$ asphyxia 237 (10.7\%) and multiple pathology 146 (6.6\%). Opinion about 
the cause of death was reserved in $310(14.1 \%)$. [Table 2]. Other minor causes include electrocution 34 (1.5\%), blunt force trauma $29(1.3 \%)$, neck injury $27(1.2 \%)$, crush injury $20(0.9 \%)$, coronary artery disease $14(0.6 \%)$, stab injury 14 $(0.6 \%)$ snake bite $5(0.2 \%)$ and cut throat injury $1(0.04 \%)$. [Table 2]

Maximum number of death occurs in month of May i.e., $215(9.7 \%)$ where as minimum number of death occurs in January i.e., 145 (6.5\%). [Table 3]

As per history, circumstantial evidences and postmortem findings it was noticed that in most of the victims the manner of death was due to accidental in nature in 952 $(43.3 \%)$ cases followed by suicidal in $502(22.8 \%)$ cases followed by natural death $380(17.2 \%)$ cases followed by unknown cause $310(14.1 \%)$ and only $53(2.4 \%)$ cases were homicidal in nature. [Fig. 2]

In present study death due to asphyxia comprises hanging $203(9.2 \%)$, drowning $16(0.7 \%)$, strangulation 9 $(0.4 \%)$, smothering $1(0.04 \%)$, throttling $3(0.1 \%)$ and chocking $2(0.09 \%)$ cases. [Fig. 3]

In present study death due to pathology comprises cardiac pathology $14(0.6 \%)$, lung pathology $11(0.5 \%)$, intra cerebral hemorrhage $10(0.4 \%)$, liver pathology 7 $(0.3 \%)$, brain pathology $6(0.2 \%)$, renal pathology $2(0.09 \%)$ cases. [Fig. 4]

Table 1: Age and sex wise distribution of cases

\begin{tabular}{|c|c|c|c|c|c|c|}
\hline \multirow[t]{2}{*}{ Age group } & \multicolumn{2}{|c|}{ Male } & \multicolumn{2}{|c|}{ Female } & \multicolumn{2}{|c|}{ Total } \\
\hline & NO. & $\%$ & NO. & $\%$ & NO. & $\%$ \\
\hline Non viable fetus & 15 & 0.6 & 18 & 0.8 & 35 & 1.5 \\
\hline 0-10 Years & 39 & 1.7 & 31 & 1.4 & 70 & 3.1 \\
\hline 11-20 Years & 166 & 7.5 & 110 & 5.0 & 276 & 12.5 \\
\hline 21-30 Years & 415 & 18.8 & 183 & 8.3 & 598 & 27.2 \\
\hline $31-40$ & 342 & 15.5 & 126 & 5.7 & 468 & 21.3 \\
\hline $41-50$ & 302 & 13.7 & 68 & 3.0 & 370 & 16.8 \\
\hline $51-60$ & 195 & 8.8 & 34 & 1.5 & 229 & 10.4 \\
\hline$>61$ & 115 & 5.2 & 39 & 1.7 & 154 & 7.0 \\
\hline
\end{tabular}

Table 2: Major cause of death

\begin{tabular}{|c|c|c|c|}
\hline Major cause of death & $\begin{array}{c}\text { Male } \\
\mathrm{N}=\mathbf{1 5 8 8}(\%)\end{array}$ & $\begin{array}{c}\text { Female } \\
\mathrm{N}=609(\%)\end{array}$ & $\begin{array}{c}\text { Total } \\
\mathbf{N}=\mathbf{2 1 9 7}(\%)\end{array}$ \\
\hline Head injury & $450(20.4 \%)$ & $98(4.4 \%)$ & $548(24.9 \%)$ \\
\hline Open & $240(10.9 \%)$ & $70(3.2 \%)$ & $310(14.1 \%)$ \\
\hline Burns & $99(4.5 \%)$ & $178(8.1 \%)$ & $277(12.6 \%)$ \\
\hline Multiple injury & $232(10.5 \%)$ & $38(1.7 \%)$ & $270(12.2 \%)$ \\
\hline Posoning & $148(6.7 \%)$ & $90(4.0 \%)$ & $238(10.8 \%)$ \\
\hline Asphyxia & $159(7.2 \%)$ & $78(3.5 \%)$ & $237(10.7 \%)$ \\
\hline Pathology & $123(5.5 \%)$ & $23(1.0 \%)$ & $146(6.6 \%)$ \\
\hline Electrocution & $23(1.0 \%)$ & $11(0.5 \%)$ & $34(1.5 \%)$ \\
\hline Blunt force trauma & $27(1.2 \%)$ & $2(0.09 \%)$ & $29(1.3 \%)$ \\
\hline Neck injury & $25(1.1 \%)$ & $2(0.09 \%)$ & $27(1.2 \%)$ \\
\hline Crush injury & $16(0.7 \%)$ & $4(0.1 \%)$ & $20(0.9 \%)$ \\
\hline Coronary artery disease & $13(0.5 \%)$ & $1(0.04 \%)$ & $14(0.6 \%)$ \\
\hline Stab injury & $13(0.5 \%)$ & $1(0.04 \%)$ & $14(0.6 \%)$ \\
\hline Non viable & $6(0.2 \%)$ & $7(0.3 \%)$ & $13(0.5 \%)$ \\
\hline Gun shot & $6(0.2 \%)$ & $1(0.04 \%)$ & $7(0.3 \%)$ \\
\hline Snake bite & $4(0.1 \%)$ & $1(0.04 \%)$ & $5(0.2 \%)$ \\
\hline Still born & $2(0.09 \%)$ & $2(0.09 \%)$ & $4(0.1 \%)$ \\
\hline Shock and hemorrhage & $0(0.0 \%)$ & $2(0.09 \%)$ & $2(0.09 \%)$ \\
\hline Scorpion bite & $1(0.04 \%)$ & $0(0.0 \%)$ & $1(0.04 \%)$ \\
\hline Cut throat injury & $1(0.04 \%)$ & $0(0.0 \%)$ & $1(0.04 \%)$ \\
\hline Total & $1588(72.2 \%)$ & $609(27.8 \%)$ & $2197(100 \%)$ \\
\hline
\end{tabular}

Table 3: Month wise distribution

\begin{tabular}{|l|c|c|c|}
\hline \multicolumn{1}{|c|}{ Month } & Male (\%) & Female (\%) & Total (\%) \\
\hline August & $138(6.2 \%)$ & $37(1.6 \%)$ & $165(5.1 \%)$ \\
\hline September & $132(6.0 \%)$ & $43(1.9 \%)$ & $175(7.9 \%)$ \\
\hline October & $137(6.2 \%)$ & $61(2.7 \%)$ & $198(9.0 \%)$ \\
\hline
\end{tabular}




\begin{tabular}{|l|c|c|c|}
\hline November & $129(5.8 \%)$ & $56(2.5 \%)$ & $185(8.4 \%)$ \\
\hline December & $132(6.0 \%)$ & $53(2.4 \%)$ & $185(8.4 \%)$ \\
\hline January & $102(4.6 \%)$ & $43(1.9 \%)$ & $145(6.5 \%)$ \\
\hline February & $107(4.8 \%)$ & $46(2.0 \%)$ & $153(6.9 \%)$ \\
\hline March & $147(6.7 \%)$ & $61(2.7 \%)$ & $208(9.4 \%)$ \\
\hline April & $140(6.3 \%)$ & $58(2.6 \%)$ & $198(9.0 \%)$ \\
\hline May & $159(7.2 \%)$ & $56(2.5 \%)$ & $215(9.7 \%)$ \\
\hline June & $152(6.9 \%)$ & $41(1.9 \%)$ & $193(8.7 \%)$ \\
\hline July & $123(5.6 \%)$ & $54(2.4 \%)$ & $177(8.0 \%)$ \\
\hline Total & $1588(72.2 \%)$ & $609(27.8 \%)$ & $2197(100 \%)$ \\
\hline
\end{tabular}

Fig. 1: Sex wise distribution $(\mathrm{N}=2197)$
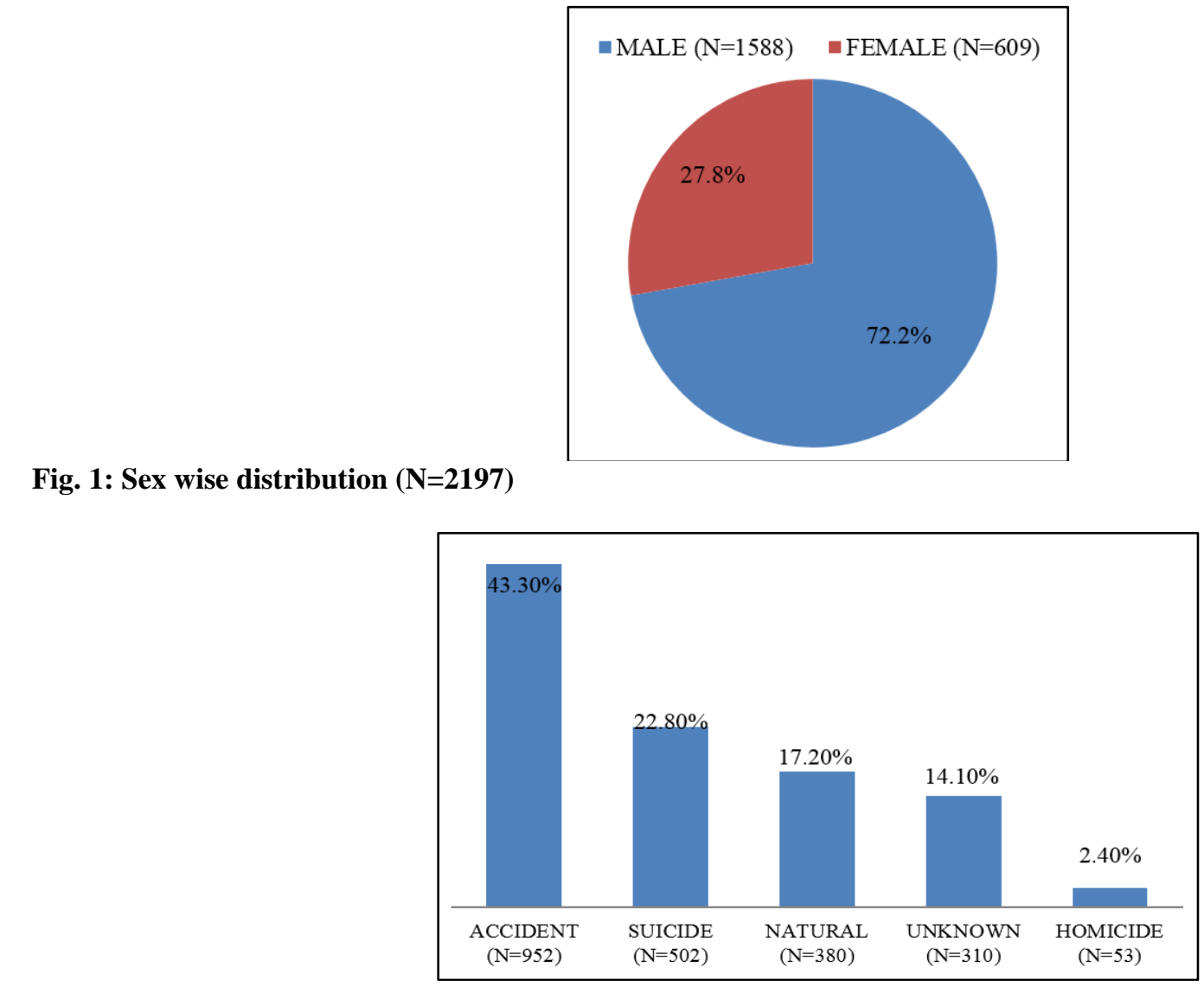

Fig. 2: Alleged manner of death $(\mathrm{N}=2197)$

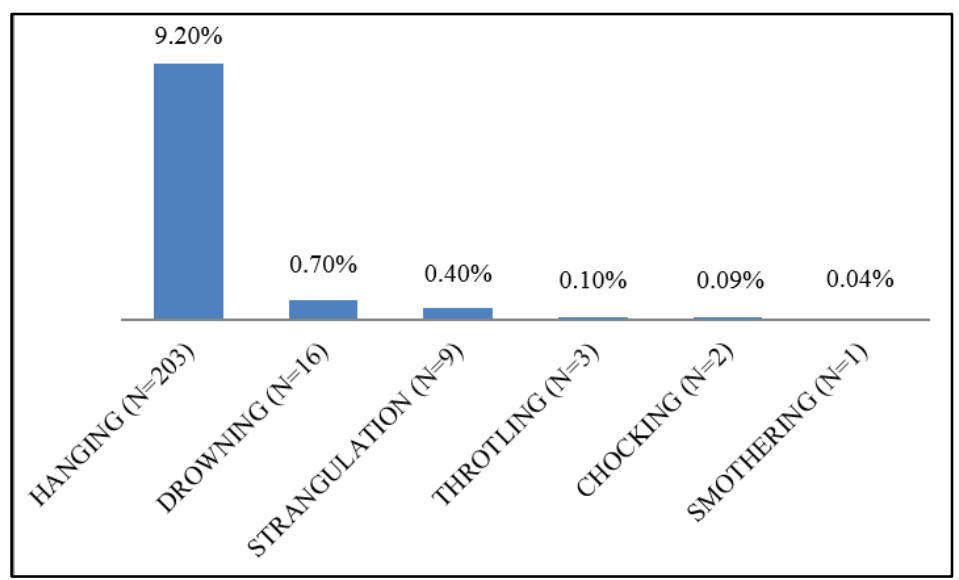

Fig. 3: Death due to asphyxia 


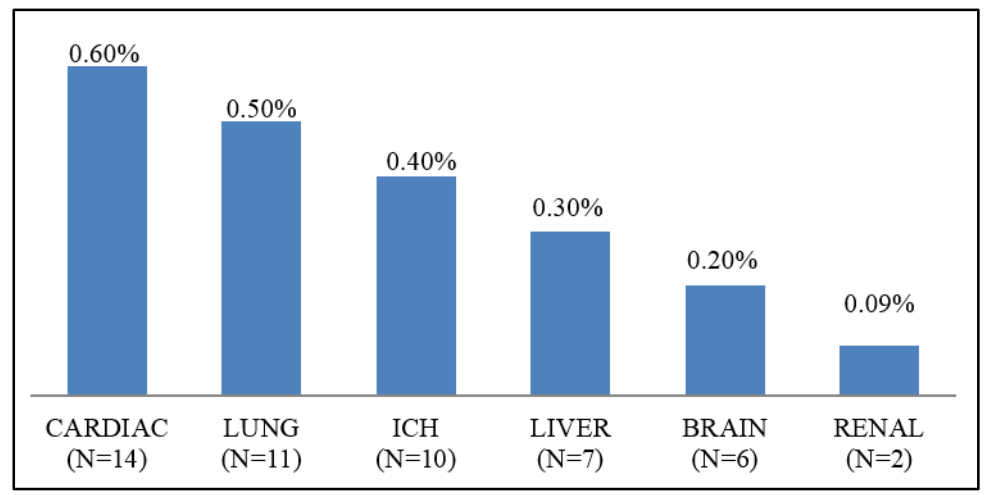

Fig. 4: Death due to pathology

\section{Discussion}

The present prospective study was carried out in the Department of Forensic Medicine \& Toxicology, M.G.M. Medical College \& M.Y. Hospital, Indore (M.P.) during the period from 1st August 2017 to 31st July 2018. It has been compared with other similar studies carried out in different parts of the world to bring out the similarities and differences.

In present study total number of postmortem examinations conducted was 2197 out of which 609 $(27.8 \%)$ were females and $1588(72.2 \%)$ were males showing less number of deaths in females as compare to males which was similar to study conducted by $\mathrm{K}$. Sundaram et al, ${ }^{10}$ Sharma B.R. et $\mathrm{al}^{11}$ and G.G. Dayanand et al. ${ }^{12}$

In our study majority of victims $598(27.2 \%)$ were in their 3rd decade, followed by in $4^{\text {th }}$ decade i.e., $468(21.3 \%)$ which was consistent with the study conducted by G.G. Dayanand et al. ${ }^{12}$ and Mandar R.S et al. ${ }^{13}$

In our study most common manner of death was accidental 952 (43.3\%), followed by suicides 502 (22.8\%) which was consistent with the study conducted by Pawar C.K. et al. ${ }^{14}$ and G.G. Dayanand et al. ${ }^{12}$ and differ from Mandar R.S et al. ${ }^{13}$ suicidal $(88.2 \%, \mathrm{n}=75)$, followed by accidental $(7.1 \%, \mathrm{n}=6)$.

In our study major causes of death comprises trauma $818(37.2 \%)$ followed by burn $277(12.6 \%)$ which was differ from K. Sundaram et al ${ }^{10}$ trauma $(27.26 \%)$ followed by asphyxia and hanging (15.3\%) and G.G. Dayanand et al. ${ }^{12}$ poisoning $124(46.61 \%)$ followed by burns 71 (26.69\%).

In the present study, the total number of hanging cases conducted were 203 [9.2\%], almost similar cases was observed by Manoj K Baishya et al, ${ }^{15}$ less number of cases was observed by Patel A P et $\mathrm{al}^{16}$ observed 332 cases of hanging in their study period.

In the present study, the total number of burn cases conducted were 277 [12.6\%] less number of cases i.e., 95 cases was observed by Mishra P.K. et $\mathrm{al}^{17}$ of burn in their study period.

In the present study, the total number of poisoning cases conducted were 238 [10.8\%] less number of cases i.e., 132 cases was observed by Gupta B.D. et $\mathrm{al}^{18}$ of poisoning in their study period.
In our study maximum number of death occurs in month of May i.e., $215(9.7 \%)$ where as minimum number of death occurs in January i.e., 145 (6.5\%). Death due to asphyxia comprises drowning $16(0.7 \%)$, strangulation 9 $(0.4 \%)$, smothering 1 (0.04\%), throttling $3(0.1 \%)$ and chocking $2(0.09 \%)$ cases. Death due to pathology comprises cardiac pathology $14(0.6 \%)$, lung pathology 11 $(0.5 \%)$, intra cerebral hemorrhage $10(0.4 \%)$, liver pathology $7(0.3 \%)$, brain pathology $6(0.2 \%)$, renal pathology $2(0.09 \%)$ cases.

\section{Conclusion}

The above study radically evaluates data pertaining to medico-legal cases brought for autopsy at a Medico-legal Centre at mortuary of M.G.M. Medical College, Indore. Medico-legal Autopsies form an integral and indispensible part of an investigation of a sudden suspicious death. As the most common cause of death was trauma due to road traffic accident it is essential to educate the general public about the road safety measures. Media, particularly, can play a more active role in this area.

Prevention is better than cure and effective prevention requires a good understanding of major risk factors. Government, NGO'S and other organizations need to intensify their efforts in raising the awareness of public at large.

The skills and experience of a Autopsy surgeon facilitate the law enforcement agencies in administration of justice and bring the guilty to the gallows. The data generated would facilitate the medicolegalist in having a greater insight in the baffling occurrence of a sudden suspicious death in their area of jurisdiction.

\section{Conflict of Interest: Nil.}

\section{References}

1. Section 174 of the Code of Criminal Procedure 1973. Available at: http://www.hyderabadpolice.gov.in/acts/CrPC.pdf (last accessed on November 10, 2018).

2. Modi a textbook of Medical Jurisprudence and Toxicology, chapter 13 post mortem examination, 25rd edn. New Delhi: LexisNexis, 2016. p285.

3. Curran WJ. The Medico-legal autopsy and Medico-legal investigation. Bull N Y Acad Med. 1971;47(7):766-775. 
4. The Punjab Medical Manual, 2nded. 1933. Superintendent, Government Printing, Punjab, Lahore; App. XXXVII: CII, Chapter X, p. 154, Para 595

5. Park's Textbook of Preventive \& Social Medicine. 19th edition 2007: $\mathrm{p} 340-345$.

6. Hogarth, J. Glossary of Health Care Terminology, WHO, Copenhagen (1978).

7. Mishra P.K., Tomar J.S. 'Profile of Death in Burn Cases: A Post-mortem Study.' JIFM. 2016;38(1):8-10.

8. Adalkha A. Organophosphate and Carbamate poisoning in Punjab. JAPI. 1988;36:210-12.

9. David Gunnell, Olive Bennewith, Keith Hawton, Sue Simkin and Nav Kapur. The epidemiology and prevention of suicide by hanging: a systematic review. Int J Epidemiol. 2005;34(2):433-442.

10. K. Sundaram. Six-year analysis of postmortem examination records at a teaching hospital - demographic profile and causes of deaths. Int J Med Sci Pubic Health. 2016;5(09);1905-1910.

11. Sharma B.R. 'Unnatural deaths in northern India a profile' JIAFM. 2004;26(4). ISSN 0971-0973

12. G.G. Dayanand. 'A Study of Demography of Medico Legal Autopsies in Bijapur. IJFMT. 2013;7(1):37-41.
13. Mandar R.S. 'Unnatural Deaths of Adult Females in South Bangalore An Autopsy Study', JIAFM. 2014;36(2):130-132.

14. Pawar C.K. 'Profile of Unnatural Deaths in Females A Retrospective Study. JIAFM. 2014;36(2):122-124.

15. Baishya Manoj K, Mahanta Putul. An Epidemiological Study of Hanging Cases Brought to the Gandhi Medical College and Hospital for Medicolegal Autopsy- A Retrospective Study. Medico-legal Update. 2014;14(2):128-129.

16. Patel A P. Study of Hanging Cases in Ahmedabad Region. $J$ Indian Acad Forensic Med. 2012;34(4):342-345.

17. Mishra P.K. 'Profile of Death in Burn Cases: A Post-mortem Study.' J Indian Acad Forensic Med. 2016;38(1):8-10.

18. Gupta B.D. 'Profile of fatal poisoning in and around Jamnagar. JIAFM. 2005;27(3):145-148.

How to cite this article: Agrawal R, Thakur P. S, Shrivastava M, Singh B. K, Pendro T. S. Demographic profile of autopsy in Indore region - One year prospective study. Indian J Forensic Community Med. 2018;5(4):245-249. 